\title{
THE EFFECT OF PROPHYLACTIC ACETAZOLAMIDE IN PATIENTS UNDERGOING EXTENSIVE RETINAL DETACHMENT REPAIR
}

\author{
BETH EDMUNDS and CHRIS R. CANNING \\ Southampton
}

\section{SUMMARY}

Encirclement of the eye as part of a retinal detachment repair is known to raise the post-operative intraocular pressure. We studied the effect of anticipating this pressure rise by giving perioperative acetazolamide to patients having vitrectomy and encirclement procedures. Two groups $(9$ with acetazolamide and 14 without) were matched for biographic variables, type of detachment and operation variables. The group given acetazolamide had lower day 1 post-operative intraocular pressures (mean $22.11 \mathrm{mmHg}$ vs $36.36 \mathrm{mmHg}$, $p=0.002$ ) and were able to go home sooner (mean 1.56 days vs 3.29 days, $p=0.001$ ). No adverse effects of short-term acetazolamide use were noted in this study. We conclude that patients having extensive scleral buckling procedures should all receive prophylactic acetazolamide unless it is specifically contraindicated.

Scleral buckling for retinal detachment is associated with raised post-operative intraocular pressure. This is particularly the case when the eye has been encircled. ${ }^{1-3}$ The result is post-operative pain, slower recovery and longer hospital stays.

Acetazolamide lowers intraocular pressure. ${ }^{4}$ This study looked at whether pre-treating patients undergoing retinal detachment surgery and encirclement with acetazolamide, either during surgery or immediately post-operatively, reduces the post-operative pressure, pain or stay in hospital.

\section{MATERIALS AND METHODS}

Two groups of patients undergoing retinal detachment surgery were compared retrospectively. Patients satisfying eligibility criteria were drawn from all those undergoing retinal detachment surgery between June 1989 and July 1993. Both groups had vitrectomy and encirclement as part of their pro-

Correspondence to: Beth Edmunds. FRCOphth. Southampton Eye Hospital, Southampton General Hospital. Tremona Road, Southampton SO16 6YD. UK. cedure. The trial group had $500 \mathrm{mg}$ acetazolamide either intravenously during the operation or in the early post-operative period. The control group did not. Patients with any conditions that could interfere independently with intraocular pressure such as previous eye surgery (apart from uncomplicated extracapsular cataract extraction with lens implant), glaucoma, diabetes or inflammatory eye disease, or age over 70 years, were excluded.

All patients underwent retinal cryopexy, subretinal fluid drainage, air/fluid exchange and $\mathrm{SF}_{6}$ gas injection. The encircling element was a 240 Mira strap and the buckle was either a 277 or 279 sutured directly to sclera and placed circumferentially. No silicone oil was used in this study. The outcome parameters assessed were the intraocular pressure on the first post-operative day, the need for postoperative opiate analgesia and the length of stay in hospital. An observer masked to the study groups assessed the indications for prolonged hospital stays in those patients who stayed longer than 1 day. Student's $t$-test assuming unequal variance was used for analysis of intraocular pressure and length of hospital stay, while Fisher's exact test was used for analysis of post-operative analgesia.

\section{RESULTS}

Fourteen patients did not receive acetazolamide and 9 did. Details of the patients are listed in Table I and the parameters that were compared between the groups in Table II.

The mean first day intraocular pressure was 22.11 $\mathrm{mmHg}$ ( $\mathrm{SD} 6.39 \mathrm{mmHg}$ ) in the acetazolamide group and 36.36 (SD $13.20 \mathrm{mmHg}$ ) in the untreated group. This difference is significant $(p=0.002)$, with a difference between means of 14.25 and $95 \%$ confidence intervals of 5.6 to 22.9 .

The mean number of days in hospital was 1.56 (SD 0.73 ) in the treated group and 3.29 (SD 1.49) in the untreated group. This was significant $(p=0.001)$, 
Table I. Comparison between groups

\begin{tabular}{|c|c|c|c|c|c|}
\hline \multirow{2}{*}{$\frac{\text { Variable }}{\text { Mean age (years) }}$} & \multicolumn{2}{|c|}{ Untreated $(n=14)$} & \multicolumn{2}{|c|}{ Treated $(n=9)$} & \multirow[b]{2}{*}{$(\mathrm{NS}, p=0.861)$} \\
\hline & 57. & & 57.11 & & \\
\hline Sex (no. of females) & 3 & $(21.4 \%)$ & 1 & $(11.1 \%)$ & $(\mathrm{NS}, p=0.963)$ \\
\hline Rhegmatogenous retinal detachment & 14 & $(100 \%)$ & 9 & $(100 \%)$ & \\
\hline Vitrectomy and encirclement & 14 & $(100 \%)$ & 9 & $(100 \%)$ & \\
\hline Mean extent of buckle (degrees) & 180 & & 142 & & $(\mathrm{NS}, p=0.379)$ \\
\hline \multicolumn{6}{|l|}{ Width of buckle } \\
\hline 277 & 3 & & 3 & & $(\mathrm{NS}, p=0.550)$ \\
\hline 279 & 9 & & 5 & & \\
\hline No buckle (encirclement only) & 2 & & 1 & & $(\mathrm{NS}, p=0.820)$ \\
\hline Prior cataract extraction & 5 & $(35.7 \%)$ & 3 & $(33.3 \%)$ & $(\mathrm{NS}, p=0.740)$ \\
\hline
\end{tabular}

Table II. Parameters compared between treated and untreated groups

\begin{tabular}{|c|c|c|}
\hline Parameter & Untreated $(n=14)$ & Treated $(n=9)$ \\
\hline Mean first post-operative intraocular pressure $(\mathrm{mmHg})$ & $\begin{array}{l}36.36(\mathrm{SD} 13.20) \\
\text { (difference between }\end{array}$ & $\begin{array}{l}22.11(\mathrm{SD} 6.39) \quad p=0.002 \\
\mathrm{~s}=14.25 .95 \% \text { confidence intervals }=5.6 \text { to } 22.9)\end{array}$ \\
\hline Mean no. of post-operative days in hospital & $\begin{array}{l}3.29(\mathrm{SD} 1.49) \\
\text { (difference between }\end{array}$ & $\begin{array}{l}1.56(\mathrm{SD} 0.73) \quad p=0.001 \\
\mathrm{~s}=1.73,95 \% \text { confidence intervals }=0.75 \text { to } 2.71)\end{array}$ \\
\hline No. of patients requiring opiate analgesia & $5(35.7 \%)$ & $1(11.1 \%) \quad(\mathrm{NS}, p=0.428)$ \\
\hline
\end{tabular}

with a difference between means of 1.73 and $95 \%$ confidence intervals of 0.75 to 2.71 . Our findings, confirmed by independent assessment by an observer masked to the trial, showed that in the majority of patients in the untreated group, raised intraocular pressure accounted for a hospital stay longer than 1 day.

One patient received opiate anaigesia in the acetazolamide group and 5 in the non-acetazolamide group. The difference was not statistically significant.

\section{DISCUSSION}

A rise in intraocular pressure following retinal detachment surgery, particularly with encirclement, is well recognised. ${ }^{1-3}$ Several mechanisms for this have been suggested. A rhegmatogenous retinal detachment may reduce the overall resistance to uveoscleral outflow, which suggests that less fluid leaves via the trabecular meshwork. When the retina is reattached, the uveoscleral route for aqueous drainage through the retinal break is rapidly sealed. ${ }^{5}$ The uveoscleral resistance suddenly increases and the trabecular outflow takes time to readjust. Scleral buckling may move the ciliary body forward with anterior displacement of the lens/iris diaphragm. ${ }^{6.7}$ An encirclement can distort and narrow the veins draining the ciliary body, causing congestion of this organ. ${ }^{8}$ This in turn can move the lens/iris diaphragm forward further and narrow the anterior chamber drainage angle with increased resistance to outflow. $6,9.10$ Intraocular inflammation may increase the resistance to aqueous outflow in the trabecular meshwork.

This raised intraocular pressure causes ocular ischaemia and affects aqueous outflow, thereby prolonging the high pressure. ${ }^{11}$ Ocular ischaemia causes pain and morbidity ${ }^{11}$ which would slow patient recovery and discharge.

The rationale for using acetazolamide pre- or intra-operatively is to abort this cycle of high pressure and ischaemia by improving ocular perfusion. Acetazolamide has a plasma half-life of 3-6 hours. We postulate that its early administration at the time of surgery, rather than awaiting ocular hypertension as a complication following surgery, can abort the spiral of raised intraocular pressure and ocular ischaemia. The results presented here bear this out. This would also explain why, even though several hours may have elapsed between acetazolamide administration and the first intraocular pressure measurement, its effects are still apparent in the better pressure levels in those patients who were treated. Although intravenous acetazolamide is quite expensive, the oral preparation is not. Indeed, when measured against the bed-days saved, these costs are small.

Acetazolamide has short-term side effects (drowsiness, numbness, tingling of extremities, fatigue, excitement, thirst, headache, dizziness, ataxia, tinnitus, hearing loss, gastrointestinal disturbances, allergic reactions), none of which were documented in the records of the patients in this study.

The authors do not have any commercial or proprietary interest in acetazolamide.

Key words: Prophylactic acetazolamide. Retinal detachment, Intraocular pressure. Hospital stay.

\section{REFERENCES}

1. Curtin VT. Management of retinal detachment. In: Duane TD, editor. Clinical ophthalmology, revised ed, vol 5. Philadelphia: JB Lippincott, 1988:Ch 16.

2. Williams GA, Aaberg TM. Techniques of scleral buckling. In: Ryan SJ, editor. Retina, 2nd ed, vol 3. St Louis: Mosby, 1994:2006. 
3. Haynie GD, D'Amico DJ. Scleral buckling surgery. In: Albert DM, Jakobiec FA, editors. Principles and practice of ophthalmology: clinical practice, 1st ed, vol 2. Philadelphia: WB Saunders, 1994:1099.

4. Friedland BR, Mallonee J, Anderson DR. Short-term dose response characteristics of acetazolamide in man. Arch Ophthalmol 1977;95:1809-12.

5. Pederson JE, Cantrill HL. Experimental retinal detachment. V. Fluid movement through the retinal hole. Arch Ophthalmol 1984;102:136-9.

6. Fiore JV, Newton JC. Anterior segment changes following the scleral buckling procedure. Arch Ophthalmol 1970;84:284-7.

7. Smith TR. Acute glaucoma developing after scleral buckling procedures. Am J Ophthalmol 1967;63: 1807-8.

8. Hayreh SS, Baines JAB. Occlusion of the vortex veins. Br J Ophthalmol 1973;57:217-38.

9. Hartley RE, Marsh RJ. Anterior depth changes after retinal detachment. Br J Ophthalmol 1973;57:546-50.

10. Melamed S, Frenkel R, Krug J, Allingham R. Trabeculectomy with resection of ciliary processes in glaucoma following scleral buckling. Ophthalmic Surg 1988;19:506-7.

11. Williams GA, Aaberg TM. Techniques of scleral buckling. In: Ryan SJ, editor. Retina, 2nd ed, vol 3. St Louis: Mosby, 1994:2006-7. 